\title{
FATORES DETERMINANTES DO TEMPO DE MACERAÇÃO DOS ALIMENTOS EM IDOSAS EDÊNTULAS TOTAIS
}

\author{
Determinant factors from edentulous aged women \\ for food maceration time
}

Ana Karênina de Freitas Jordão do Amaral (1), Hilton Justino da Silva (2), Etenildo Dantas Cabral (3)

\begin{abstract}
RESUMO
Objetivo: determinar o tempo de maceração dos alimentos pão e bolo, e analisar se há associação com: idade, tempo de edentulismo, grau de abertura oral máximo e dimensão vertical do 1/3 inferior da face. Métodos: desenvolvido na Clínica-Escola de Odontologia da Universidade Federal de Pernambuco, com idosas edêntulas totais atendidas no segundo período letivo do ano de 2006; amostra: 33 participantes. Para mensurar a dimensão vertical foi utilizado método fonético com paquímetro digital, o mesmo para mensurar o grau de abertura oral máximo. Para o tempo de maceração foram utilizados pão francês e bolo, usando um cronômetro. Cada alimento foi macerado três vezes, sendo considerado apenas o último tempo de duração, em segundos. Foi realizado cálculo das medidas descritivas: média, mediana, mínimo, máximo, desvio padrão. Para análise comparativa das variáveis foi utilizado teste Qui-Quadrado de independência ou Teste exato de Fisher quando necessário, sendo as conclusões tomadas ao nível de significância de 5\%. Resultados: tempo médio de maceração do bolo: $18,1 \pm 6,2$ segundos; do pão: $38,3 \pm 22,9$ segundos; idade média: $67,4 \pm 6,8$ anos; grau de abertura oral máximo médio: 46,1 $\pm 7,0$ milímetros; dimensão vertical do 1/3 inferior da face média: $55,2 \pm 6,2$ milímetros; tempo de edentulismo médio: $22,9 \pm 12,98$ anos. Os tempos de maceração não foram significantes quando associados às variáveis estudadas, pois todos os $p$-valores foram maiores que 0,05. Conclusão: não foram encontradas evidências estatísticas de que os fatores estudados tenham associação com os tempos de maceração dos alimentos na amostra estudada.
\end{abstract}

DESCRITORES: Idoso; Perda de Dente; Mastigação

\section{INTRODUÇÃO}

Os avanços nos estudos de saúde têm repercutido no aumento da expectativa de vida do homem ${ }^{1}$. No entanto, a situação de saúde bucal dos idosos brasileiros é precária e tem sido esquecida quando são discutidas as condições de saúde dessa população ${ }^{2,3}$.

(1) Fonoaudióloga; Fonoaudióloga do Centro de Reabilitação Francisco Loureiro, Jaboatão dos Guararapes, PE; Mestre em Patologia pela Universidade Federal de Pernambuco.

(2) Fonoaudiólogo; Professor Adjunto do Departamento de Fonoaudiologia da Universidade Federal de Pernambuco, UFPE, Recife, PE; Doutor em Nutrição pela Universidade Federal de Pernambuco.

(3) Odontólogo; Professor Adjunto do Departamento de Anatomia da Universidade Federal de Pernambuco, UFPE, Recife, PE; Doutor em Odontologia Preventiva e Social pela Universidade Federal de Pernambuco.

Conflito de interesses: inexistente
A prevalência do edentulismo no Brasil é uma das mais elevadas do mundo. Em Recife, é possível encontrar um percentual de $61,7 \%$ de edentulismo em idosos institucionalizados e $52,1 \%$ para os não institucionalizados ${ }^{2}$.

Infelizmente, a perda total dos dentes ainda é vista pela sociedade como algo inerente ao enveIhecimento, e muitos idosos desdentados totais não usam próteses dentárias e acabam encontrando formas de adaptação da mastigação ${ }^{4,5}$.

A expressão maceração refere-se ao processo no qual o desdentado total realiza amassamento do alimento, preparando um bolo alimentar diante das condições anatômicas que possui. Esta nomenclatura surgiu a partir da atuação junto a idosos institucionalizados edêntulos totais, que não faziam uso de próteses dentárias. Observando como realizavam amassamento dos alimentos utilizando a língua contra o palato duro, além da movimentação aumentada das estruturas adjacentes, surgiu 0 
interesse em nomear esta adaptação da forma de mastigar. Eram idosos que conservavam sua alimentação mesmo diante das alterações anatômicas (ósseas e musculares), encontrando adaptações pessoais, ao mesmo tempo comuns. Além disso, a maioria apresentava como queixa a demora para preparar o bolo alimentar.

Partindo disto, surgiram questionamentos sobre quais seriam os fatores possivelmente determinantes do tempo de duração da maceração dos alimentos. Portanto, este trabalho teve como objetivo determinar o tempo de maceração dos alimentos de idosas edêntulas totais e analisar se existe associação com a idade, tempo de edentulismo, grau de abertura oral máximo e dimensão vertical do 1/3 inferior da face, considerando a hipótese de que o tempo de maceração dos alimentos seja associado a tais fatores.

\section{MÉTODOS}

Tratou-se de um estudo observacional, analítico e transversal, que foi desenvolvido na Clínica Escola do Curso de Odontologia, da Universidade Federal de Pernambuco.

Por meio do termo de consentimento livre e esclarecido (Resolução MS/CNS/CNEP n.196/96 de 10 de outubro de 1996), as idosas voluntárias permitiram a realização da coleta dos dados. Por protocolo específico (Figura 1), foram obtidos os dados de identificação, tempo de edentulismo, dimensão vertical do $1 / 3$ inferior da face e grau de abertura oral máximo com o uso de paquímetro digital, e o tempo de maceração dos alimentos com cronômetro.

A amostra de referência do presente estudo teve como critérios de inclusão:

- Mulheres com idade igual ou superior a 60 anos;

- Idosas edêntulas totais que procuraram atendimento no local, durante o segundo semestre letivo de 2006 (novembro de 2006 a março de 2007);

- Todas as idosas que concordassem em participar voluntariamente.

- A utilização exclusiva do gênero feminino se deu devido ao fato de representar mais de $90 \%$ dos idosos atendidos no local de estudo.

- A amostra teve como critérios de exclusão:

- Mulheres idosas que possuíssem doenças neuromusculares e/ou degenerativas;

- Mulheres idosas que não conseguissem responder / colaborar com a coleta espontaneamente.

Para mensurar a dimensão vertical do 1/3 inferior da face (Figura 2), a voluntária foi colocada em posição confortável, sentada, com cabeça e tronco eretos. Em seguida, foram marcados dois pontos na face com caneta dermatográfica preta, sendo um localizado na base do nariz ( $s n$ : ponto subnasal) e outro no mento (gn: gnátio), ambos na linha mediana ${ }^{6}$.

Foi utilizado o método fonético, reconhecidamente utilizado na área odontológica como o mais seguro para mensurar a dimensão vertical, pois considera o espaço funcional de pronúncia. Este último não é o mesmo que o espaço funcional livre; pois o primeiro é resultado de atividade muscular e é mais constante, e o segundo ocorre devido ao relaxamento muscular, sendo mais variável. Neste

PROTOCOLO PARA COLETA DOS DADOS

Nome:

Data de nascimento:

idade:

Data da entrevista:

Tempo de edentulismo: anos

Grau de abertura oral máximo em $\mathrm{mm}$ :

Dimensão vertical do $1 / 3$ inferior da face em mm:

Maceração dos alimentos

Tempo em segundos

Pão:

Bolo:

Figura 1 - Protocolo utilizado para realização da coleta dos dados 
método, pois, solicita-se que o voluntário pronuncie uma palavra, como "Mississipi" (que contém sons sibilantes), por três vezes consecutivas e mantenha-se na posição final por alguns segundos para que se possa mensurar a distância entre a base do nariz e o mento com a haste para mensurar estruturas externas do paquímetro digital ${ }^{7}$.

Para mensurar ao grau de abertura oral máximo (Figura 3), a voluntária foi mantida na mesma postura, e foi solicitado que a partir de uma posição confortável da mandíbula, abrisse a boca o máximo possível. Foi traçada uma linha vertical, registrandose em milímetros a partir da inserção do frênulo do lábio superior até a inserção do frênulo do lábio inferior.

Para cronometrar o tempo de maceração dos alimentos, utilizou-se pão francês e bolo. Estes alimentos foram padronizados nas seguintes

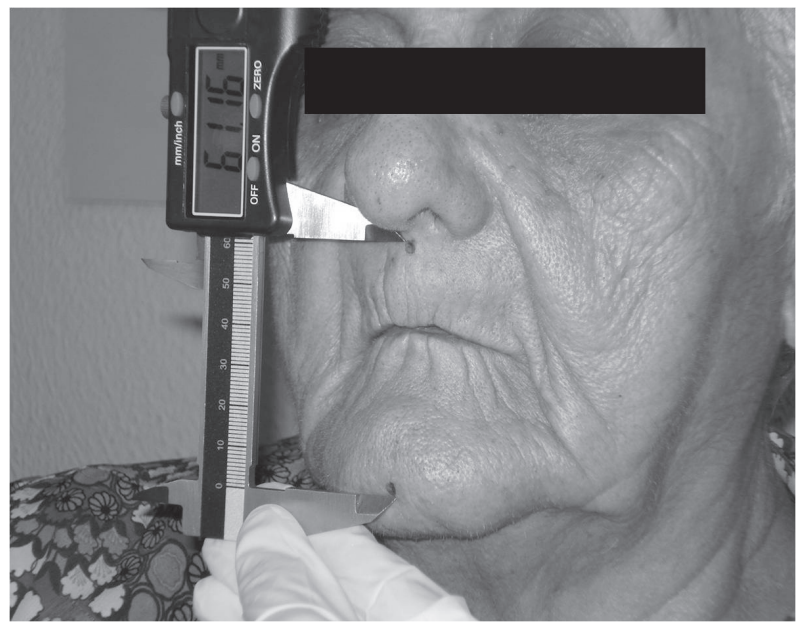

Figura 2 - Mensuração da dimensão vertical do $1 / 3$ inferior da face

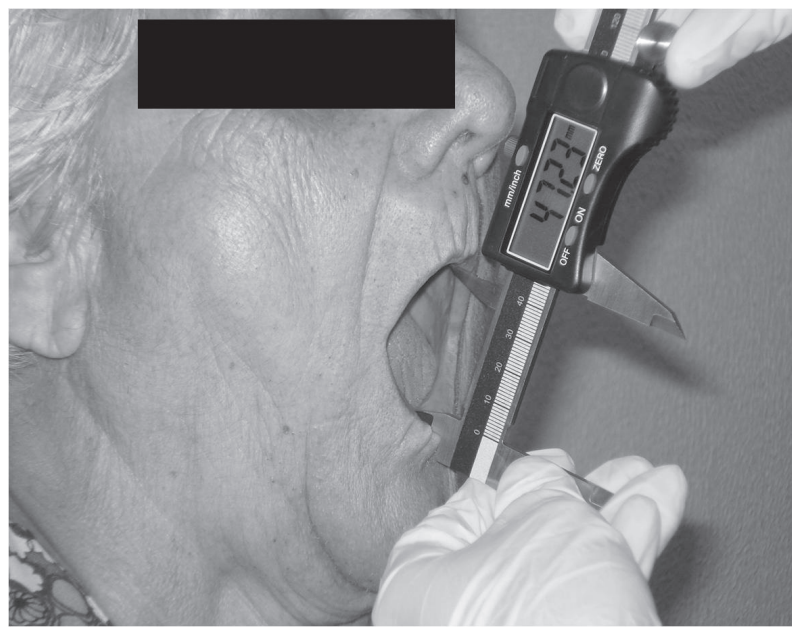

Figura 3 - Mensuração da abertura oral máxima porções: 1 fatia de bolo de forma redonda tamanho padrão (marca Dona Benta ${ }^{\circledR}$, sabor limão) com $1,5 \mathrm{~cm}$ de espessura e 1 fatia de pão francês de $50 \mathrm{~g}$ com $1,5 \mathrm{~cm}$ de espessura, retirada da porção central. Sendo oferecido primeiramente o bolo, e depois o pão.

A voluntária recebeu os alimentos, um por vez, os introduziu na cavidade oral e realizou a maceração, que foi filmada e cronometrada por três vezes consecutivas, para cada alimento, registrando-se o tempo de maceração em segundos. Apenas o terceiro tempo de maceração dos alimentos registrado foi considerado para análise.

O trabalho foi submetido ao Comitê de Ética em Pesquisa com Seres Humanos da Universidade Federal de Pernambuco, sendo aprovado sob protocolo de número 212/2006.

As variáveis estudadas foram apresentadas por meio de tabelas, com cálculo de medidas descritivas. Para análise comparativa das variáveis foi utilizado o teste Qui-Quadrado de independência ou o teste exato de Fisher quando necessário, sendo todas as conclusões tomadas ao nível de significância de $5 \%$. Os softwares utilizados foram o Excel 2000 e o SPSS v8.0. A fim de verificar existência de associação entre as variáveis estudadas e os tempos de maceração dos alimentos foram criadas duas variáveis derivadas a partir dos tempos de maceração medianos.

\section{RESULTADOS}

A amostra foi composta por 33 idosas edêntulas totais, salientando-se que não usavam próteses dentárias até o momento da coleta.

A Tabela 1 apresenta a distribuição das voluntárias, quanto à idade, tempo de maceração do pão, do bolo, grau de abertura oral máximo, dimensão vertical do $1 / 3$ inferior da face e tempo de edentulismo.

É possível observar que a idade média foi de 67,4 anos, sem grandes variações. Observa-se razoável variação nos valores do tempo de maceração do bolo (18,1 s), mas para o tempo médio de maceração do pão (38,3 s), assim como para os valores do tempo de edentulismo (22,9 anos) essa variação foi ainda maior. O grau de abertura oral máxima (média de 46,1 mm) e a dimensão vertical do 1/3 inferior da face (média 55,2 mm) apresentaram valores sem grandes variações.

A Tabela 2 apresenta a distribuição das idosas edêntulas totais quanto às variáveis estudadas, segundo tempo de maceração do bolo. Observase não haver relação estatisticamente significante entre as mesmas e o tempo de maceração do bolo. 
Tabela 1 - Distribuição das idosas edêntulas totais quanto às variáveis estudadas

\begin{tabular}{lcccccc}
\hline Variáveis & N & Mínimo & Máximo & Mediana & Média & Desvio \\
\hline Idade (em anos) & 33 & 60,0 & 83,0 & 65,0 & 67,4 & 6,8 \\
Tempo de Maceração Pão (em segundos) & 33 & 10,0 & 113,0 & 33,0 & 38,3 & 22,9 \\
Tempo de Maceração do Bolo (em segundos) & 33 & 6,0 & 34,0 & 17,0 & 18,1 & 6,2 \\
Grau de Abertura Oral Máximo (em mm) & 33 & 22,8 & 56,3 & 47,4 & 46,1 & 7,0 \\
Dimensão Vertical do 1/3 inferior da face (em mm) & 33 & 46,1 & 68,6 & 53,6 & 55,2 & 6,2 \\
Tempo de edentulismo (em anos) & 33 & 10,0 & 53,0 & 20 & 22,9 & 12,98 \\
\hline
\end{tabular}

$\mathrm{mm}$ - milímetros

Tabela 2 - Distribuição das idosas edêntulas totais quanto às variáveis estudadas, segundo tempo de maceração do bolo

\begin{tabular}{|c|c|c|c|c|c|}
\hline \multirow{3}{*}{ Características Gerais } & \multicolumn{4}{|c|}{ Tempo de Maceração do Bolo } & \multirow{3}{*}{ p-valor } \\
\hline & \multicolumn{2}{|c|}{ Até 17" } & \multicolumn{2}{|c|}{$>17^{\prime \prime}$} & \\
\hline & $\mathbf{N}$ & $\%$ & $\mathbf{N}$ & $\%$ & \\
\hline \multicolumn{6}{|l|}{ Idade } \\
\hline Até 65 anos & 9 & 52,9 & 8 & 50,0 & \\
\hline$>65$ anos & 8 & 47,1 & 8 & 50,0 & 0,866 \\
\hline \multicolumn{6}{|c|}{ Grau de Abertura Oral Máximo } \\
\hline Até $47,37 \mathrm{~mm}$ & 10 & 58,8 & 7 & 43,8 & \\
\hline$>47,37 \mathrm{~mm}$ & 7 & 41,2 & 9 & 56,2 & 0,387 \\
\hline \multicolumn{6}{|c|}{ Dimensão Vertical do $1 / 3$ inferior da face } \\
\hline Até $53,6 \mathrm{~mm}$ & 7 & 41,2 & 10 & 62,5 & \\
\hline$>53,6 \mathrm{~mm}$ & 10 & 58,8 & 6 & 37,5 & 0,221 \\
\hline \multicolumn{6}{|l|}{ Tempo de edentulismo } \\
\hline Até 20 anos & 10 & 58,8 & 9 & 56,2 & \\
\hline$>20$ anos & 7 & 41,2 & 7 & 43,8 & 0,881 \\
\hline
\end{tabular}

Teste exato de Fisher $\mathrm{p} \leq 0,05$ (significantes); > maior; mm - milímetros

A Tabela 3 mostra a distribuição das idosas edêntulas totais quanto às variáveis estudadas, segundo tempo de maceração do pão. Observa-se também não haver relação estatisticamente significante entre as variáveis e o tempo de maceração do pão.

\section{DISCUSSÃO}

Poucos estudos descrevem sobre tempo de mastigação, e menos ainda sobre tempo de maceração de alimentos por idosos edêntulos totais. Neste trabalho, o tempo de maceração do pão obteve uma média de 38,3 segundos, sendo superior a outro estudo que determinou o tempo de mastigação e que estudou adultos dentados ${ }^{8}$. Nesse aspecto é compreensível, pelo simples fato de que as idosas avaliadas tenham sido desdentadas totais e assim apresentassem um prejuízo aumentado na formação do bolo alimentar. Resultados semelhantes aos apresentados foram encontrados por outros autores ${ }^{9,10}$. No entanto, é difícil comparar os resultados em maiores detalhes, pois as condições anatomofuncionais são diferentes.

Durante este estudo, foi observado que a maior parte das idosas, devido às atuais condições do sistema estomatognático, partia o pedaço de pão oferecido com as mãos. Este fato foi entendido como uma adaptação das mesmas para facilitar a colocação do alimento na cavidade oral, devido à dificuldade de incisão. Resultados semelhantes foram descritos por outros autores ${ }^{5,11}$.

As idosas edêntulas totais apresentaram um tempo de maceração do bolo médio de 18,1 
Tabela 3 - Distribuição das idosas edêntulas totais quanto às variáveis estudadas, segundo tempo de maceração do pão

\begin{tabular}{|c|c|c|c|c|c|}
\hline \multirow{3}{*}{ Características Gerais } & \multicolumn{4}{|c|}{ Tempo de Maceração do Pão } & \multirow{3}{*}{ p-valor } \\
\hline & \multicolumn{2}{|c|}{ Até 33" } & \multicolumn{2}{|c|}{ > 33" } & \\
\hline & $\mathbf{N}$ & $\%$ & $\mathbf{N}$ & $\%$ & \\
\hline \multicolumn{6}{|l|}{ Idade } \\
\hline Até 65 & 9 & 52,9 & 8 & 50,0 & \\
\hline$>65$ & 8 & 47,1 & 8 & 50,0 & 0,866 \\
\hline \multicolumn{6}{|c|}{ Grau de Abertura Oral Máximo } \\
\hline Até $47,37 \mathrm{~mm}$ & 8 & 47,1 & 9 & 56,2 & \\
\hline$>47,37 \mathrm{~mm}$ & 9 & 52,9 & 7 & 43,8 & 0,598 \\
\hline \multicolumn{6}{|c|}{ Dimensão Vertical do $1 / 3$ inferior da face } \\
\hline Até $53,6 \mathrm{~mm}$ & 9 & 52,9 & 8 & 50,0 & \\
\hline$>53,6 \mathrm{~mm}$ & 8 & 47,1 & 8 & 50,0 & 0,866 \\
\hline \multicolumn{6}{|l|}{ Tempo de edentulismo } \\
\hline Até 20 anos & 10 & 58,8 & 9 & 56,2 & \\
\hline$>20$ anos & 7 & 41,2 & 7 & 43,8 & 0,881 \\
\hline
\end{tabular}

Teste exato de Fisher $\mathrm{p} \leq 0,05$ (significantes); > maior; mm - milímetros

segundos, e referiram ser muito mais fácil preparar esse alimento quando comparado ao pão. Poucos estudos foram encontrados utilizando o bolo como alimento para avaliar a mastigação. Outro estudo determinou a velocidade da mastigação e o número de ciclos mastigatórios e encontrou-se o tempo de mastigação do bolo: 17.4, 23 e 30.7 segundos, para os volumes pequeno, médio e grande respectivamente. Não encontraram diferença significativa na velocidade da mastigação entre os alimentos, o número de ciclos mastigatórios e o tempo de mastigação ${ }^{12}$. A média do tempo de maceração para o bolo das idosas edêntulas do presente estudo se aproximou do tempo de mastigação do volume pequeno do bolo do estudo referido anteriormente.

Outros estudos utilizam alimentos diferentes, como: maçã, banana, castanha de caju, folha de parafilme e pão ${ }^{13}$; bolacha tipo "água e sal" 14; e salsicha ${ }^{15}$.

As idosas apresentaram idade entre 60 e 80 anos, com média de 67,4 anos não apresentando grandes variações de idade. Resultados semelhantes foram encontrados por outros autores ${ }^{2,3,16,17}$. Em estudo citado, também na cidade de Recife, com 198 idosos institucionalizados, a média de idade obtida foi igual a 71,13 anos, variando entre $60 \mathrm{e}$ 97 anos, sendo todos igualmente edêntulos totais e maioria mulheres ${ }^{3}$.

Alguns autores referem que encontraram mulheres que se tornaram desdentadas totais com idade média de 39,3 anos, e os homens com idade média de 48,1 anos ${ }^{18}$. Nesse último estudo, as mulheres da pesquisa correspondem a aproximadamente o dobro dos homens, chegam a idades mais avançadas, e, portanto, apresentam mais tempo de edentulismo que eles. Duzentas e vinte e duas das 315 mulheres se tornaram desdentadas totais há mais de 20 anos. Resultados semelhantes foram encontrados por outros autores ${ }^{19,20}$.

No presente estudo foi possível constatar que tanto a idade como o tempo de edentulismo não tiveram associação significativa com o tempo de maceração dos alimentos. Ao contrário do que se esperava, o fato de ter grande período de tempo de edentulismo não influenciou no tempo da maceração. Nem mesmo a idade, não se constituiu num fator determinante do tempo de maceração.

As idosas deste estudo apresentaram grau de abertura oral máximo que variou entre $22,8 \mathrm{~mm}$ e $56,3 \mathrm{~mm}$, alcançando média de 46,1 mm. Resultados divergentes foram encontrados por outros autores ${ }^{21}$, mas resultados semelhantes foram encontrados em outros estudos 22,23. Destaca-se que este valor não foi tão reduzido àquele considerado normal em pessoas dentadas naturais, e mesmo naquelas idosas que apresentaram valores abaixo dos $40 \mathrm{~mm}$ não houve significância estatística quando comparada ao tempo de maceração dos alimentos. Esta variável, pois, não foi fator determinante para os tempos de maceração da amostra.

A dimensão vertical do $1 / 3$ inferior da face da amostra atingiu uma média de $55,2 \mathrm{~mm}$, tendo 
como mínimo 45,1 mm e máximo 68,6 mm. Resultados similares foram encontrados ${ }^{24}$, mas outros estudos 4,5,25 encontraram resultados bastante divergentes. Os valores encontrados na amostra estudada não tiveram relação com os tempos de duração da maceração dos alimentos, não sendo, portanto, a dimensão vertical do 1/3 inferior da face fator determinante dos tempos de maceração.

\section{CONCLUSÃO}

Os tempos de maceração dos alimentos bolo e pão (média de 18,1 e 38,3 segundos, respectivamente) variaram entre as idosas do presente estudo, sobretudo o tempo de maceração do pão, mas não foram estatisticamente associados às variáveis estudadas.

\begin{abstract}
Purpose: to determine time for food maceration of bread and cake; and consider whether there is an association among: age; edentulism time; oral opening maximum; vertical dimension. Methods: a study developed in a Dentistry Clinic School, Pernambuco Federal University (UFPE), with old women with total edentulous attended during second time school in 2006; sample: 33 participants. In order to measure the vertical dimension, a phonetic method was used, with digital pachymeter, the same used to measure the maximum oral opening. For maceration time we used French bread and cake, employing a stopwatch. Each food was macerated three times, and we considered the last time duration, in seconds. Descriptive analysis was performed, with tabular presentation, in addition to descriptive measures' calculation: average, median, minimum, maximum, standard deviation. For comparative analysis of qualitative variables we used independence chi-square test or Fisher's exact test whenever necessary, and all conclusions were taken at a $5 \%$ significance level. Results: cake average maceration: $18.1 \pm 6.2$ seconds; bread: $38.3 \pm 22.9$ seconds; average age: $67.4 \pm 6.8$ years; average oral opening maximum: $46.1 \pm 7,0 \mathrm{~mm}$; average vertical dimension: $55.2 \pm 6.2 \mathrm{~mm}$; average edentulism time $22,9 \pm 12,98$ years. Maceration times have not been meaningful when associated with the studied variables, because all p-values have been greater than 0.05 . Conclusion: no statistics evidences were found that the studied factors were linked to food maceration times in the studied sample.
\end{abstract}

KEYWORDS: Aged; Tooth Loss; Mastication

\section{REFERÊNCIAS}

1. Caldas Júnior AF, Caldas KU, Oliveira MRM, Amorim AA, Barros PMF. O impacto do edentulismo na qualidade de vida de idosos. Rev Cienc Méd. 2005 maio/jun; 14(3):229-38.

2. Caldas Júnior $A F$, Figueiredo ACL, Soriano EP, Sousa EHA, Melo JBG, Vilela AS. Prevalência de cárie e edentulismo em idosos de Recife Pernambuco - Brasil. Rev Bras Cienc Saúde. 2002; 6(2):113-22.

3. Boing AF, Peres MA, Kovaleski DF, Zange SE, Antunes JLF. Estratificação sócio-econômica em estudos epidemiológicos de cárie dentária e doenças periodontais: características da produção na década de 90. Cad Saúde Pública. 2005 maio/jun; 21(3):673-8.

4. Cunha CC, Zuccolotto MCC, Bataglion C. Avaliação da eficiência mastigatória em paciente portador de prótese total. Rev Assoc Paul Cirur Dent. 1999 maio/jun; 53(3):214-7.
5. Cunha CC, Felício CM, Bataglion C. Condições miofuncionais orais em usuários de próteses totais. Pró-Fono. 1999; 11(1):21-6.

6. Cattoni DM. O uso do paquímetro na motricidade orofacial: procedimento e avaliação. 1. ed. Barueri: Pró-Fono; 2006.

7. Paes-Júnior TJA, Jóias RM, Kimpara ET, Cerveira Netto $\mathrm{H}$, Zambotto J. Análise da dimensão vertical de repouso em indivíduos usuários de próteses totais mucossuportadas. Rev Odontol Araçatuba. 2004 jan-jun; 25(1):22-7.

8. Melo TM, Arrais RD, Genaro KF. Duração da mastigação de alimentos com diferentes consistências. Rev Soc Bras Fonoaudiol. 2006; 11(3):170-4.

9. Monteiro MP, Carneiro FP, Felipe NAP, Motta AR. Mastigação e dispepsia funcional: um novo campo de atuação. Rev CEFAC. 2005 jul./set; 7(3):340-7. 10. Silva LG, Goldenberg M. A mastigação no processo de envelhecimento. Rev. CEFAC. 2001; 3(1):27-35. 
11. Magluf LRF, Lucena JA, França MCGR. Aspectos miofuncionais orofaciais em idosos anadônticos que utilizam ou não próteses dentárias móveis. XIV Congresso Brasileiro de Fonoaudiologia; 2006; Salvador, BA. Rev Soc Bras Fonoaudiol. 2006; Suplemento Especial:32-56.

12. Gavião MBD, Bilt AV. Salivary secretion and chewing: stimulatory effects from artificial and natural foods. J Appl Oral Sci. 2004; 12(2):159-63.

13. Berretin-Félix G, Genaro KF, Trindade IEK, Trindade Júnior AS. Masticatory function in temporomandibular dysfunction patients: electromyographic evaluation. J Appl Oral Sci. 2005; 13(4):360-5.

14. Prado MMS, Borges TF, Prado CJ, Gomes VL, Neves FD. Função mastigatória de indivíduos reabilitados com próteses totais mucoso suportadas. Pesq Bras Odontoped Clin Integr. 2006 set/dez; 6(3):259-66.

15. Felício CM, Melchior MO, Silva MAMR, Celeghini RMS. Desempenho mastigatório em adultos relacionado com a desordem temporomandibular e com a oclusão. Pró-Fono. 2007 abr/jun; 19(2):151-8.

16. Barreto KML, Carvalho EMF, Falcão IV, Lessa FJD, Leite VMM. Perfil sócio-epidemiológico demográfico das mulheres idosas da Universidade Aberta à Terceira Idade no estado de Pernambuco. Rev Bras Saúde Matern Infant. 2003 jul/set; 3(3):339-54.

17. Garcez-LemeLE, LemeMD, EspinoDV.Geriatrics in Brazil: a big country with big opportunities. J Am Geriatr Soc. 2005; 53(11):2018-22.
18. Oliveira TRC, Frigerio MLMA. Avaliação nutricional e protética de pacientes senescentes desdentados - estudo comparativo entre pacientes portadores de próteses totais mucoso-suportadaimplanto-retidas e próteses totais convencionais. RPG Rev Pós Grad. 2005; 12(2):255-63.

19. Braga SRS, Telarolli Júnior R, Braga AS, Catirse ABCEB. Efeito do uso de próteses na alimentação de idosos. Rev. Odontol. UNESP. 2002; 31(1):71-81. 20. Kruger E, Tennant M, Badrian B, Gorgy S, Bruce D. Oral health of aged in patients. Austr J Age. 2004 dec; 23(4):172-6.

21. Bianchini EMG, Paiva G, Andrade CRF. [Mandibular movements in speech: interference of temporomandibular disfunction according to pain indexes]. Pró-Fono. 2007 jan/abr; 19(1):7-18.

22. Lima MM, Benevides SD. Maximum amplitude of the buccal opening in people submitted to the radiotherapy in region of head and neck. Int $\mathrm{J}$ Dentistr. 2005; 4(1):15-20.

23. Porto VC, Salvador MCG, Conti PCR. Avaliação da posição condilar em desdentados totais, através de planigrafias da ATM. Rev Fac Odontol Bauru. 2002; 10(2):81-7.

24. Ricci WA. Disfunção craniomandibular em pacientes desdentados totais com alteração da dimensão vertical [dissertação]. Araraquara (SP): Universidade Estadual Paulista; 2002.

25. Guedes LU, Freiria CLG. As alterações de motricidade orofacial em idosos internos em uma instituição de longa permanência na cidade de Belo Horizonte. XIV Congresso Brasileiro de Fonoaudiologia; 2006; Salvador, BA. Rev Soc Bras Fonoaudiol. 2006; Suplemento Especial: 277.

RECEBIDO EM: 10/02/2009

ACEITO EM: 28/08/2009

Endereço para correspondência:

Ana Karênina de Freitas Jordão do Amaral

Rua Manoel Graciliano de Souza, 1103 ap. 101-B

Olinda - PE

CEP: $53050-120$

E-mail: akfjafono@ hotmail.com 